\title{
Isotropic source components of events in the 2019 Ridgecrest, California, earthquake sequence
}

\author{
Yifang Cheng1, Xin Wang, ${ }^{2,3,4}$, Zhongwen Zhan ${ }^{4}$ and Yehuda Ben-Zion ${ }^{1,5}$
}

${ }^{1}$ Department of Earth Sciences, University of Southern California, Los Angeles, CA, USA

${ }^{2}$ Key Laboratory of Earth and Planetary Physics, Institute of Geology and Geophysics, Chinese Academy of Sciences, Beijing, China

${ }^{3}$ CAS Center for Excellence in Deep Earth Science, Beijing, China

${ }^{4}$ Seismological Laboratory, California Institute of Technology, Pasadena, CA, USC

${ }^{5}$ Southern California Earthquake Center, University of Southern California, Los Angeles, CA, USA

Corresponding author: Xin Wang (wangxin@ mail.iggcas.ac.cn)

\section{Key Points:}

- 50 out of $224 \mathrm{M} \geq 3$ earthquakes show considerable isotropic components not resolved without near-fault data

- Events with large isotropic components occurred early in the sequence near rupture ends and fault intersections

- Rock fracturing in earthquake source volumes likely contributes significantly to the isotropic components

This article has been accepted for publication and undergone full peer review but has not been through the copyediting, typesetting, pagination and proofreading process, which may lead to differences between this version and the Version of Record. Please cite this article as doi: 10.1029/2021GL094515.

This article is protected by copyright. All rights reserved. 


\begin{abstract}
We investigate the non-double-couple components of $224 M \geq 3$ earthquakes in the 2019 $M_{\mathrm{w}} 7.1$ Ridgecrest sequence, which occurred on a complex fault system in the Eastern California Shear Zone. Full moment tensors are derived using waveform data from near-fault and regional stations with a generalized cut-and-paste inversion and 3D velocity and attenuation models. The results show limited Compensated Linear Vector Dipole components, but considerable explosive isotropic components (5-15\% of the total moments) for approximately 50 earthquakes. Most of these events occur between the $M_{\mathrm{w}} 6.4$ foreshock and one day after the $M_{\mathrm{w}} 7.1$ mainshock and are mainly distributed around the rupture ends and fault intersections. The percentage of isotropic components is reduced considerably when data recorded by near-fault stations are not included in the inversions, highlighting the importance of near-fault data. The results suggest that highfrequency damage-related radiation and other local dilatational processes are responsible for the observed isotropic source terms.
\end{abstract}

\title{
Plain Language Summary
}

Earthquakes occur when rocks below the surface break and move rapidly. Deriving earthquake source mechanisms provides information on the involved physical processes. We examine source mechanisms of $M \geq 3$ earthquakes in the $2019 M_{\mathrm{w}} 7.1$ Ridgecrest sequence, using waveforms from 39 near-fault and regional stations. Many earthquakes are found to have considerable isotropic radiation that is not expected for pure slip motion along faults. The isotropic radiation reflect motions normal to the faults that may be cauased by complex fault geometry, transient fluid pressure effects, and generation of microcracks in the rupture zones. We systematically investigate the possibility of each mechanism by analyzing the spatiotemporal variations of events with considerable isotropic components. The results suggest that rock damage in the rupture zone likely provides a major contribution to the isotorpic radiation.

\section{Introduction}

Earthquakes are typically assumed to have pure deviatoric sources (Zhu \& Helmberger, 1996; Clinton et al., 2006) because the isotropic components are usually very small (Miller et al., 1998; Ma et al., 2012, Ross et al., 2015). However, even small isotropic components within rupture zones can have fundamental implications for many aspects of earthquake physics including the energy partitioning between dissipation and seismic radiation, crack vs. pulse modes of rupture, and amplitude ratio of the generated P and S waves (e.g., Brune et al., 1993; Ben-Zion et al., 2001; Kurzon et al., 2019). The P/S amplitude ratio of seismic radiation is also important for a discrimination of explosions from earthquakes (e.g., Bukchin et al., 2001; Patton and Taylor, 2011; Stroujkova, 2018).

Transient volumetric changes in earthquake source volumes can be caused by a wide variety of processes. It is well known that brittle fracturing is accompanied by dilatational effects (e.g., Brace et al., 1966; Lockner et al., 1991; Renard et al. 2019). Dynamic reduction of elastic moduli in earthquake rupture zones reduces the capacity of the affected local volume to sustain elastic strain energy and produces damage-related radiation with a large isotropic component (Ben-Zion \& Ampuero, 2009; Ben-Zion and Lyakhovsky 2019). This and other dynamic dilatational effects around a propagating rupture front are associated with short wavelengths that decay rapidly with distance from the fault (Lyakhovsky and Ben-Zion, 2020). Additional mechanisms that can generate high frequency isotropic source terms include fracture

This article is protected by copyright. All rights reserved. 
opening/closing caused by fluid pressure variations (e.g. Miller et al., 1998, Dreger et al., 2000; Martínez- Garzón et al., 2017), ruptures on rough or nonplanar surfaces (e.g. Castro, 1991; Julian et al., 1998), elastic collisions along sliding surfaces (Lomnitz-Adler, 1991; Tsai and Hirth, 2020), and near-source anisotropy (Vavryčuk, 2005).

Resolving reliably small isotropic source terms of crustal earthquakes is a challenging task because they are associated with rapidly decaying high frequency waves and require dense station coverage, high frequency records, and accurate earthquake locations. Due to these challenges, other parameters have been used to infer on the possible existence of isotropic source components. Examples include large P/S amplitude ratios (Castro et al., 1991; Castro \& BenZion, 2013), reduced directivity effects of high frequency waves (Spudich \& Chiou, 2008), and strong transient rotation of double-couple (DC) focal mechanisms (Ross \& Ben-Zion, 2013). The recent increase of high-quality near-fault seismic data improved the ability to derive reliable source mechanisms of earthquakes, some of which include considerable explosive isotropic components (Stierle et al., 2014; Ross et al., 2015; Hayashida et al., 2020). Nevertheless, the number of studies resolving isotropic source terms of regular crustal earthquakes remains rather limited.

The 2019 Ridgecrest, California, earthquake sequence in southern California, which included the $M_{w} 6.4$ event on July 4, the $M_{w} 7.1$ mainshock on July 6 , and over $200 M \geq 3.0$ earthquakes within the first month after the $M_{w} 6.4$ event, provides important opportunities to analyze earthquake source processes (Figure 1). The $M_{\mathrm{w}} 6.4$ and $M_{\mathrm{w}} 7.1$ earthquakes exhibited lower-than-average rupture speeds (Liu et al., 2019). The earthquake sequence had abundant aftershocks (Ross et al., 2019; Shelly, 2020) that occurred in broad zones with complex geometries and rock damage (Chen et al., 2020; Xu et al., 2020; Jia et al., 2020; Qiu et al., 2021). The Ridgecrest sequence occupied a complex fault network with many previously unmapped faults, suggesting that many events in the sequence may generate damage-related radiation. The area was well monitored by a regional network of broadband seismic stations. It also has a highquality regional 3D seismic velocity model obtained using full waveform inversion with nearsurface velocity structures incorporated from geotechnical borehole data (Lee et al., 2014). In the following, we perform a comprehensive analysis of isotropic source terms of earthquakes in the Ridgecrest sequence in an effort to explore the governing earthquake physics.

\section{Data}

We derive full moment tensor solutions for $224 M \geq 3$ earthquakes in the 2019 Ridgecrest sequence using locations from the refined local earthquake catalog of Ross et al. (2019). For each event, we utilize waveform data recorded by 39 SCSN stations within $100 \mathrm{~km}$ from the epicenters (Figure 2a). The moment tensor inversions use the 3D Southern California Earthquake Center (SCEC) community velocity model for southern California (Lee et al., 2014) and the 3D attenuation model for the region (Hauksson and Shearer, 2006). The waveform data are obtained from the Southern California Earthquake Data Center (http://scedc.caltech.edu). The usage of near-fault stations and 3D velocity model can help to better constrain the moment tensor solutions, and is especially useful for analysis of isotropic source terms.

\section{Method}

\subsection{Source decomposition}

This article is protected by copyright. All rights reserved. 
We implement the source decomposition of Zhu and Ben-Zion (2013) to quantify the full tensorial components of each event. The seismic potency tensor $P_{i j}$ is first decomposed into isotropic (ISO) and deviatoric components:

$$
P_{i j}=\frac{P_{0}}{\sqrt{2}}\left(\frac{\zeta}{\sqrt{3}} \delta_{i j}+\sqrt{1-\zeta^{2}} D_{i j}\right),
$$

where $P_{0}$ is the scalar potency, $\delta_{i j}$ is the Kronecker delta, $\zeta$ quantifies the strength of the isotropic term, and $D_{i j}$ is a normalized deviatoric tensor. The dimensionless parameter $\zeta$ is given by:

$$
\zeta=\sqrt{\frac{2}{3}} \frac{\operatorname{tr}(P)}{P_{0}}
$$

and it varies from -1 (implosion) to 1 (explosion). The normalized deviatoric tensor $D_{i j}$ is decomposed into DC and Compensated Linear Vector Dipole (CLVD) components:

$$
D_{i j}=\sqrt{1-\chi^{2}} D_{i j}^{D C}+\chi D_{i j}^{C L V D}
$$

where $\chi$ represents the strength of the CLVD component with a range from -0.5 to 0.5 . The relative strength of the individual components is quantified by the square ratio of the scalar moment of each component relative to the total scalar potency:

$$
\begin{gathered}
\Lambda_{\mathrm{ISO}}=\operatorname{sgn}(\zeta) \zeta^{2}, \\
\Lambda_{\mathrm{DC}}=\left(1-\zeta^{2}\right)\left(1-\chi^{2}\right), \\
\Lambda_{\mathrm{CLVD}}=\operatorname{sgn}(\chi)\left(1-\zeta^{2}\right) \chi^{2} .
\end{gathered}
$$

The sum of the absolute values of the relative strengths is:

$$
\left|\Lambda_{\text {ISO }}\right|+\Lambda_{\text {DC }}+\left|\Lambda_{\text {CLVD }}\right|=1 \text {. }
$$

Note that the maximum CLVD and ISO strengths are $25 \%$ and $100 \%$, respectively. This decomposition can be used efficiently for full moment tensor inversion with a grid search over the possible DC, ISO, and CLVD components within the allowable ranges.

\subsection{Automated moment tensor inversion}

We employ an automated moment tensor inversion algorithm (Wang and Zhan, 2020a) that fits the observed body and surface waves at stations with epicentral distance less than $100 \mathrm{~km}$ using the 3D velocity and attenuation models for southern California (section 2). We first calculate numerically 3-D Green's functions (including the near-, intermediate-, and far-field terms) for all events and stations, using the 3D finite difference code of Graves (1996). We then invert the velocity waveforms for source terms using the gCAP3D method (Zhu and Zhou, 2016). The source parameters include strike, dip, rake, $M_{w}$, hypocentral depth, ISO term $\zeta$, and CLVD term $\chi$. For each combination of parameters, we calculate synthetic waveforms using the 3D Green's functions, window the synthetic waveforms into Pnl and surface waves, and estimate the fit between the synthetic and observed waveforms. The lengths of waveform segments and frequency bands (approximately between 0.03 to $0.3 \mathrm{~Hz}$ ) are automatically chosen based on the magnitude of the earthquake as in Wang and Zhan (2020a).

To accommodate inaccuracies in the assumed velocity model and earthquake locations, we allow time shifts between the observations and synthetics to maximize their cross-correlation coefficients. The time shifts provide information on the relative accuracy of the earthquake locations and the used velocity and attenuation models. We also automatically control the data quality and optimize the inversion by iteratively rejecting or reducing the weight of waveform segments that are too complicated to be fitted with synthetic waveforms (Wang and Zhan, 2020a). The horizontal locations of events are fixed to those in Ross et al., (2019) during the waveform inversion, but we search over different depths to find the best-fitting focal depths

This article is protected by copyright. All rights reserved. 
associated with the minimum misfit and maximum number of waveform segments. The uncertainties of the final moment tensor solutions are estimated using a bootstrapping method that estimates source parameters using data from randomly selected $90 \%$ of the stations in the original database (Zhan et al., 2012; Ross et al., 2015; Wang and Zhan, 2020a). More details about the automated moment tensor inversion method are presented in previous publications (Wang \& Zhan, 2020a, 2020b). Note that we only apply this method to $M<6$ earthquakes. For larger earthquakes, the point source assumption used in our moment tensor inversion is not valid and finite-source inversion is more appropriate (e.g. Ross et al., 2019).

The method is illustrated in Figure 2 with inversion results for an $M_{\mathrm{w}} 4.1$ event, which occurred on 05 July 2019 12:38 near the $M_{\mathrm{w}} 7.1$ epicenter. The resolved best-fitting depth is at $9.5 \mathrm{~km}$, with average waveform cross-correlation above 85\% (Figure 2b), and most waveforms are well-fitted with the synthetic waveforms. Figure $2 \mathrm{c}$ shows the relative misfit in the moment tensor lune-diagram (Tape and Tape, 2012). The best solution has positive isotropic component with considerably smaller misfit compared with other solutions. Well-constrained full moment tensors based on high-quality waveforms, 3D structural model and automated algorithm, allow us to systematically investigate the solutions and possible causes of the non-double-couple (nonDC) components.

\section{Results}

We derive full moment tensor solutions for 224 aftershocks of the $2019 M_{\mathrm{w}} 7.1$ Ridgecrest earthquake, and about 50 of these have considerably large non-DC components (5\%-15\%). The derived non-DC components can have several causes including uncertainties in the inversion procedure, heterogeneous and anisotropic velocity structure, and genuine non-DC earthquake processes. To evaluate the influence of different velocity models, Wang and Zhan (2020a) compared moment tensors solved using 1D and 3D velocity models and found that the incorporation of a 3D velocity model can dramatically decrease the percentage of non-DC components. A similar result is documented in the Supplementary Material (Text S1 and Figure S1), highlighting the importance of using a 3D velocity model for moment tensor inversions. There are about 50 events with fairly large non-DC components, which cannot be explained by the errors in the 3D velocity model, given the relatively long-period waveforms used in inversion. In addition to velocity structure effects, we test the robustness of the non-DC components by performing 3D moment tensor inversions using different source constraints (Section 4.1.1, 4.1.2) and minimum station distance cutoffs (Section 4.1.3). The spatiotemporal variations of the non-DC components are analyzed in Section 4.2.

\subsection{Robustness analysis of non-DC component 4.1.1 Misfit Reduction}

It is well-known that adding model parameters can reduce the data misfit of an inversion. However, if the incorporation of additional parameters does not significantly reduce the misfit, the added parameters may not be meaningful and the solved parameters may not be reliable. To evaluate the significance of the resolved non-DC components, we perform a series of inversions using different source constraints, including pure DC sources, pure deviatoric (CLVD + DC) sources, cases with only DC and isotropic terms (ISO + DC), and full moment tensor sources $(\mathrm{CLVD}+\mathrm{ISO}+\mathrm{DC})$. We compare the relative misfit change $R M C_{i j}$ of the results using source constraint $i$ relative to results using source constraint $j$ by:

This article is protected by copyright. All rights reserved. 


$$
R M C_{i ; j}=\frac{\text { Misfit }_{i}-\text { Misfit }_{j}}{\text { Misfit }_{j}} \times 100 \%,
$$

where Misfit ${ }_{i}$ is the total weighted waveform misfit between the observations $u(t)$ and the synthetic waveforms $s(t-\tau)$ using source constrain $i$ :

$$
\text { Misfit }_{i}=\sum_{k} w_{k} \times\|u(t)-s(t-\tau)\|^{2} .
$$

The weighting factor to segment $w_{k}$ is determined using both the waveform cross-correlation and the misfit between the observed and synthetic waveforms (for more details, see Wang and Zhan, 2020a).

Figures $3 \mathrm{a}$ and $3 \mathrm{~b}$ present the variations of $R M C_{D C+C L V D ; D C}$ and $R M C_{D C+C L V D+I S O ; D C+C L V D}$ versus the CLVD strengths $(\chi)$. Almost all events show reduced misfits with the incorporation of a CLVD component, with a misfit reduction that is overall proportional to the absolute CLVD strength. Some events with large CLVD strength have more than 5\% misfit reduction. Figures $3 \mathrm{c}$ and $3 \mathrm{~d}$ show corresponding results that compare the relative misfit changes for inversions incorporating isotropic components with cases assuming CLVD+DC and DC sources versus the resolved ISO strengths $(\zeta)$. The misfit reduction shows again a close correlation with the absolute value of ISO strength. When $|\zeta|$ is smaller than $0.2\left(\left|\Lambda_{\text {ISO }}\right|<4 \%\right)$, most misfit reductions are less than $1 \%$. However, there are considerable numbers of earthquakes having $|\zeta|$ larger than $0.2\left(\left|\Lambda_{\text {ISO }}\right|>4 \%\right)$ and misfit reduction larger than $2 \%$. Most events with misfit reduction larger than $2 \%$ have explosive ISO terms (Figure 3c, 3d). The large misfit reductions after the incorporation of CLVD and ISO components in the inversions suggest that these earthquakes are not pure double-couples, and that the resolved non-DC components provide useful information about the physical processes associated with these earthquakes.

\subsubsection{Trade-offs between CLVD and ISO components}

A number of studies showed that there are trade-offs between isotropic and verticallyoriented CLVD components for deep earthquakes recorded by distant stations, with station coverage primarily around the edge of the focal sphere (Kawakatsu 1991, 1996; Hara et al., 1996). However, shallow crustal earthquakes have much better coverage above and around the events. Ross et al. (2015) examined trade-offs between the CLVD and isotropic components for shallow crustal earthquakes in the San Jacinto fault zone, using synthetic tests based on a 1D velocity model and a station configuration with epicentral distances between 40 to $300 \mathrm{~km}$. Their results indicated insignificant trade-offs between the CLVD and isotropic components in such cases.

To examine further trade-offs between ISO and CLVD terms, we use the 3D velocity and attenuation models for southern California (section 2) and stations within $100 \mathrm{~km}$ epicentral distance. We compare the solved CLVD strength with and without isotropic components (DC + CLVD vs. DC + CLVD + ISO) (Figure 3e), and the solved isotropic strength with and without CLVD components (DC+ISO vs. DC + CLVD + ISO) (Figure 3f). The different assumed cases have insignificant impact on the solved CLVD and isotropic strengths (Figures 3e-f), suggesting that limited trade-offs exist between these components. Furthermore, based on the comparisons in Figures $3 a$ and $3 b$, most events with substantial misfit reductions show negative CLVD strength. However, only positive CLVD components cause trade-offs with explosive isotropic components for strike-slip mechanisms (Ross et al., 2015). We therefore conclude that the observed explosive isotropic components are unlikely to have significant trade-offs with CLVD components.

This article is protected by copyright. All rights reserved. 


\subsubsection{The effect of near-fault data on the resolved isotropic components}

In addition to trade-offs, different station coverages can impact the solved non-DC components through the signals they are able to record above the noise level (e.g., Kwiatek and Ben- Zion, 2016). This is especially important for high-frequency waves that may reflect key aspects of the local governing physics and decay strongly with propagation distance. To analyze the impact of near-fault data on the resolved isotropic components, we use three events with the largest ISO components and three with the smallest for comparison (Figure 4). We first invert their moment tensors using all available stations within $100 \mathrm{~km}$ epicentral distance (Leftmost solution in each subfigure). We then iteratively invert the moment tensors by gradually removing the near-fault data until only three stations remain (at least three stations were used to ensure the reliability of moment tensor inversion). Figure 4 shows the variations of $\left|\Lambda_{\text {ISO }}\right|$ and $\left|\Lambda_{\text {CLVD }}\right|$ with the minimum epicentral station distance used in the inversions. When gradually removing nearfault data for the events with the largest ISO components, the $\left|\Lambda_{\text {ISO }}\right|$ decreases from over $15 \%$ to around $5 \%$ while the $\left|\Lambda_{\text {CLVD }}\right|$ does not show significant changes (Figure $4 \mathrm{a}, 4 \mathrm{c}, 4 \mathrm{e}$ ). The incorporation of more near-fault data also helps to suppress solution uncertainties, which further demonstrates the robustness of the resolved non-DC components using near-fault data. In contrast, for events with the smallest ISO components, the resolved non-DC components do not show strong changes with the minimum station distance cutoff (Figure 4b, 4d, 4f).

\subsection{Spatiotemporal variations of non-DC components}

Figure 1 shows spatiotemporal variations of the derived non-DC components. Most events do not show large CLVD components (Figure 1a). In contrast, over 50 events have 5\%-15\% isotropic components. Approximately 20 of them occurred before the $M_{\mathrm{w}} 7.1$ mainshock and are located between the $M_{\mathrm{w}} 6.4$ and the $M_{\mathrm{w}} 7.1$ epicenters. After the $M_{\mathrm{w}} 7.1$ mainshock, most of the events with large ISO components occurred within 1 day. They are mainly located around fault intersections that are either NW to the $M_{\mathrm{w}} 7.1$ hypocenter or SE to the $M_{\mathrm{w}} 6.4$ hypocenter. Additional events with large ISO components are located around the NW and SE ends of the rupture zone. On the other hand, in the NW aftershock zone with splay faults and subvertical antithetic faults and the SE aftershock zone with subparallel faults, there are just a few events with large ISO components. The maximum value of the isotropic components decays with time after the occurrence of the $M_{\mathrm{w}} 7.1$ earthquake (Figure S2a).

Additionally, we calculate the cumulative density functions (CDFs) of the percentage of isotropic component in three time periods: between the $M_{\mathrm{w}} 6.4$ and $M_{\mathrm{w}} 7.1$ earthquakes, within 1 day after the $M_{\mathrm{w}} 7.1$ mainshock, and between 1 to 2 days after the $M_{\mathrm{w}} 7.1$ earthquake. In these time periods, the percentages of events with $>5 \%$ ISO components are, respectively, 40\%, 22\%, and $6 \%$ (Figure S2b), exhibiting a clear temporal decreasing pattern. Since other earthquake attributes like magnitude and depth also show systematic variations relative to the major ruptures (Cheng and Ben-Zion, 2020), we compare these attributes with the value of non-DC components. Most events with large non-DC components have magnitude ranging from 3 to 4 (Figure S3b, S3d) and the values of non-DC components do not show a clear depth dependency (Figure S3a, S3c), suggesting that the observed spatiotemporal variations of non-DC components are not dominated by variations of earthquake magnitude and depth.

\section{Discussion}

Isotropic source terms of earthquakes can have important implications for various topics including the energy partitioning between P and S waves (Kwiatek \& Ben-Zion, 2013),

This article is protected by copyright. All rights reserved. 
discrimination between earthquakes and explosions (Patton and Taylor, 2011; Stroujkova, 2018), generated frictional heat (Brune et al., 1993) and other aspects of earthquake ruptures (Ben-Zion, 2001). However, resolving isotropic components of regular crustal earthquakes is very challenging due to the dominance of shear deformation, limited seismic data, uncertainties in the inversion procedures and low-resolution velocity models (Russakoff et al., 1997; Lyakhovsky and Ben-Zion, 2020). These difficulties may produce improperly constrained isotropic components and lead to misinterpretation of source processes (Vavryčuk et al., 2008). The analysis done in this work includes near-fault data, is accompanied by the examination of tradeoff effects, and is based on a version of the "cut and paste" inversion algorithm not very sensitive to modest errors in the velocity model (e.g. Zhu \& Helmberger, 1996; Ross et al., 2015).

Several features of our results suggest that the resolved isotropic components are robust. The incorporation of isotropic components reduces over $1 \%$ of the data misfits of some events (Figure 3b, 3c). The resolved isotropic components do not show considerable changes for different frequency contents (Figure S4). There are limited trade-offs between the isotropic and CLVD components of the analyzed events (Figure 3d). Many adjacent earthquakes with similar ray paths have very different isotropic components (Figures 1 and S5), indicating that the resolved isotropic components are not caused by errors in the structural model (or instruments). In addition, there are clear correlations between the events with significant isotropic components, fault geometry and mainshock time (Figure 1), suggesting that they are likely caused by local physical processes. Mechanisms that can produce isotropic source terms include fault-normal motion generated by ruptures on non-planar faults (Castro et al., 1991; Lomnitz-Adler, 1991; Julian et al., 1998), tensile faulting in an extensional stress regime possibely augmented by involvement of fluids (Sibson, 1994, Vavryčuk 2002, Stierle et al., 2014), and damage-related radiation generated by dynamic reduction of elastic moduli in the rupture zones (Ben-Zion and Ampuero, 2009; Ben-Zion and Lyakhovsky, 2019; Lyakhovsky and Ben-Zion, 2020).

The relatively large number of the derived full moment tensor solutions for $M \geq 3$ earthquakes (Figure 1) allows us to assess the likely physical processes responsible for the observed isotropic components. A tensile stress regime is not consistent with the dominant strike-slip regime indicated by the focal mechanisms of events between the $M_{\mathrm{w}} 6.4$ and $M_{\mathrm{w}} 7.1$ earthquakes (Cheng and Ben-Zion, 2020; Sheng and Meng, 2020). There is also no clear reason why fluid effects would concentrate in the locations of the events that have significant isotropic components. Moreover, non-planar fault geometries or fluid-related tensile faulting do not explain why the strength of the CLVD components is very limited and why the strength of the isotropic components decayed so fast in time ( 1 days) after the mainshock. On the other hand, rock damage in earthquake source volumes is likely to be more pronounced for events near fault intersections and ends of the rupture zone. It is also likely to be stronger for early aftershocks, since later events may occur in already faulted materials. This is consistent with the pattern observed in Figure 1, suggesting that damage-related radiation may be a dominant source of the observed isotropic components.

As illustrated in Figures 4 and S3, most events with significant isotropic components have $M$ $<4$, and the ability to resolve isotropic source terms depends strongly on the availability of nearfault data. This is because volumetric source terms are associated with short wavelengths proportional to the rupture zone width that decay rapidly with distance from the fault, in contrast to the deviatoric terms that have wavelengths proportional to the rupture length (Lyakhovsky and Ben-Zion, 2020). Earthquakes may commonly generate a small amount of isotropic radiation, because of one or several of the discussed mechanisms, which is not resolved in typical far-field

This article is protected by copyright. All rights reserved. 
data. Additional deployments of near-fault sensors will provide improved data for detailed investigations of earthquake source processes (e.g. Hayashida et al., 2020).

\section{Data Availability Statement}

The employed earthquake catalog of Ross et al., (2019) is available online (at https://scedc.caltech.edu/data/qtm-ridgecrest.html). The used earthquake waveform data is available from the Southern California Earthquake Data Center (http://scedc.caltech.edu). The used moment tensor solutions are available through the supporting information (Dataset S1 and Dataset S2) and the Mendeley Data (https://dx.doi.org/10.17632/w4t3k63779.1) (Cheng et al., 2021).

\section{Acknowledgments}

The manuscript benefitted from useful comments by two anonymous referees and editor German Prieto. The research was supported by the Southern California Earthquake Center (based on NSF Cooperative Agreement EAR-1600087 and USGS Cooperative Agreement G17AC00047). Xin Wang acknowledges support from the Young Elite Scientists Sponsorship Program by CAST (grant 2020QNRC001).

\section{References}

Ben-Zion, Y. (2001). Dynamic ruptures in recent models of earthquake faults. Journal of the Mechanics and Physics of Solids, 49(9), 2209-2244.

Ben-Zion, Y., \& Ampuero, J. P. (2009). Seismic radiation from regions sustaining material damage. Geophysical Journal International, 178(3), 1351-1356.

Ben-Zion, Y., \& Lyakhovsky, V. (2019). Representation of seismic sources sustaining changes of elastic moduli. Geophysical Journal International, 217(1), 135-139, doi: 10.1093/gji/ggz018.

Brace, W. F., Paulding Jr, B. W., \& Scholz, C. H. (1966). Dilatancy in the fracture of crystalline rocks. Journal of Geophysical Research, 71(16), 3939-3953.

Brune, J. N., Brown, S., \& Johnson, P. A. (1993). Rupture mechanism and interface separation in foam rubber models of earthquakes: a possible solution to the heat flow paradox and the paradox of large overthrusts. Tectonophysics, 218(1-3), 59-67.

Bukchin, B. G., Mostinsky, A. Z., Egorkin, A. A., Levshin, A. L., \& Ritzwoller, M. H. (2001). Isotropic and nonisotropic components of earthquakes and nuclear explosions on the Lop Nor test site, China. In Monitoring the Comprehensive Nuclear-Test-Ban Treaty: Surface Waves (pp. 1497-1515). Birkhäuser, Basel.

Castro, R. R., Anderson, J. G., \& Brune, J. N. (1991). Origin of high P/S spectral ratios from the Guerrero accelerograph array. Bulletin of the Seismological Society of America, 81(6), 22682288.

Castro, R. R., \& Ben- Zion, Y. (2013). Potential Signatures of Damage- Related Radiation from Aftershocks of the 4 April 2010 (M w 7.2) El Mayor-Cucapah Earthquake, Baja California, México. Bulletin of the Seismological Society of America, 103(2A), 1130-1140.

Chen, K., Avouac, J. P., Aati, S., Milliner, C., Zheng, F., \& Shi, C. (2020). Cascading and pulselike ruptures during the 2019 Ridgecrest earthquakes in the Eastern California Shear Zone. Nature communications, 11(1), 1-8.

This article is protected by copyright. All rights reserved. 
Cheng, Y., \& Ben- Zion, Y. (2020). Variations of Earthquake Properties Before, During, and After the 2019 M7. 1 Ridgecrest, CA, Earthquake. Geophysical Research Letters, 47(18), e2020GL089650.

Cheng, Y., Wang, X., Zhan, Z., \& Ben-Zion, Y. (2021), "Moment tensor solutions of events in the 2019 Ridgecrest, California, earthquake sequence", Mendeley Data, V2, doi: 10.17632/w4t3k63779.2.

Clinton, J. F., Hauksson, E., \& Solanki, K. (2006). An evaluation of the SCSN moment tensor solutions: robustness of the $\mathrm{M}$ w magnitude scale, style of faulting, and automation of the method. Bulletin of the Seismological Society of America, 96(5), 1689-1705.

Dreger, D. S., Tkalčić, H., \& Johnston, M. (2000). Dilational processes accompanying earthquakes in the Long Valley Caldera. Science, 288(5463), 122-125.

Graves, R. W. (1996). Simulating seismic wave propagation in 3D elastic media using staggeredgrid finite differences. Bulletin of the seismological society of America, 86(4), 1091-1106.

Hara, T., Kuge, K., \& Kawakatsu, H. (1996). Determination of the isotropic component of deep focus earthquakes by inversion of normal-mode data. Geophysical Journal International, 127(2), 515-528.

Hauksson, E., \& Shearer, P. M. (2006). Attenuation models (QP and QS) in three dimensions of the southern California crust: Inferred fluid saturation at seismogenic depths. Journal of Geophysical Research: Solid Earth, 111(B5).

Hayashida, Y., Matsumoto, S., Iio, Y., Sakai, S. I., \& Kato, A. (2020). Non- Double- Couple Microearthquakes in the Focal Area of the 2000 Western Tottori Earthquake (M 7.3) via Hyperdense Seismic Observations. Geophysical Research Letters, 47(4), e2019GL084841.

Jia, Z., Wang, X., \& Zhan, Z. (2020). Multifault Models of the 2019 Ridgecrest Sequence Highlight Complementary Slip and Fault Junction Instability. Geophysical Research Letters, 47(17), e2020GL089802.

Julian, B. R., Miller, A. D., \& Foulger, G. R. (1998). Non- double- couple earthquakes 1. Theory. Reviews of Geophysics, 36(4), 525-549.

Kawakatsu, H. (1991). Insignificant isotropic component in the moment tensor of deep earthquakes. Nature, 351(6321), 50-53.

Kawakatsu, H. (1996). Observability of the isotropic component of a moment tensor. Geophysical Journal International, 126(2), 525-544.

Kurzon, I., V. Lyakhovsky and Y. Ben-Zion, (2019). Dynamic rupture and seismic radiation in a damage-breakage rheology model, 176, 1003-1020, Pure and Applied Geophysics, doi: 10.1007/s00024-018-2060-1.

Kwiatek, G., \& Ben- Zion, Y. (2013). Assessment of P and S wave energy radiated from very small shear- tensile seismic events in a deep South African mine. Journal of Geophysical Research: Solid Earth, 118(7), 3630-3641.

Kwiatek, G., \& Ben- Zion, Y. (2016). Theoretical limits on detection and analysis of small earthquakes. Journal of Geophysical Research: Solid Earth, 121(8), 5898-5916, doi:10.1002/2016JB012908.

Lee, E. J., Chen, P., Jordan, T. H., Maechling, P. B., Denolle, M. A., \& Beroza, G. C. (2014). Full- 3- D tomography for crustal structure in southern California based on the scatteringintegral and the adjoint- wavefield methods. Journal of Geophysical Research: Solid Earth, 119(8), 6421-6451.

This article is protected by copyright. All rights reserved. 
Liu, C., Lay, T., Brodsky, E. E., Dascher- Cousineau, K., \& Xiong, X. (2019). Coseismic rupture process of the large 2019 Ridgecrest earthquakes from joint inversion of geodetic and seismological observations. Geophysical Research Letters, 46(21), 11820-11829.

Lockner, D., Byerlee, J. D., Kuksenko, V., Ponomarev, A., \& Sidorin, A. (1991). Quasi-static fault growth and shear fracture energy in granite. Nature, 350(6313), 39-42, doi:10.1038/350039a0.

Lomnitz- Adler, J. (1991). Model for steady state friction. Journal of Geophysical Research: Solid Earth, 96(B4), 6121-6131.

Lyakhovsky, V., \& Ben-Zion, Y. (2020). Isotropic seismic radiation from rock damage and dilatancy. Geophysical Journal International, 222(1), 449-460.

Ma, K. F., Lin, Y. Y., Lee, S. J., Mori, J., \& Brodsky, E. E. (2012). Isotropic events observed with a borehole array in the Chelungpu fault zone, Taiwan. Science, 337(6093), 459-463.

Martínez- Garzón, P., Kwiatek, G., Bohnhoff, M., \& Dresen, G. (2017). Volumetric components in the earthquake source related to fluid injection and stress state. Geophysical Research Letters, 44(2), 800-809.

Miller, A. D., Foulger, G. R., \& Julian, B. R. (1998). Non- double- couple earthquakes 2. Observations. Reviews of Geophysics, 36(4), 551-568.

Patton, H. J.,\& Taylor, S.R., (2011). The apparent explosion moment: Inferences of volumetric moment due to source medium damage by underground nuclear explosions, J. Geophys. Res., 116, B03310, doi:10.1029/2010JB007937.

Qiu, H., Y. Ben-Zion, R. Catchings, M. R. Goldman, A. A. Allam, and J. Steidl (2021). Seismic imaging of the Mw 7.1 Ridgecrest earthquake rupture zone from data recorded by dense linear arrays, J. Geophys., Res., 126, e2021JB022043, doi: 10.1029/2021JB022043.

Renard, F., J. McBeck, N. Kandula, B. Cordonnier, P. Meakin, and Y. Ben-Zion (2019), Volumetric and shear processes in crystalline rock approaching faulting, Proc. Natl. Acad. Sci. U. S. A., 116(33), 16234-16239, doi:10.1073/pnas.1902994116.

Ross, Z. E., \& Ben- Zion, Y. (2013). Spatio- temporal variations of double- couple aftershock mechanisms and possible volumetric earthquake strain. Journal of Geophysical Research: Solid Earth, 118(5), 2347-2355.

Ross, Z. E., Ben-Zion, Y., \& Zhu, L. (2015). Isotropic source terms of San Jacinto fault zone earthquakes based on waveform inversions with a generalized CAP method. Geophysical Journal International, 200(2), 1269-1280.

Ross, Z. E., Idini, B., Jia, Z., Stephenson, O. L., Zhong, M., Wang, X., ... \& Jung, J. (2019). Hierarchical interlocked orthogonal faulting in the 2019 Ridgecrest earthquake sequence. Science, 366(6463), 346-351.

Russakoff, D., Ekström, G., \& Tromp, J. (1997). A new analysis of the great 1970 Colombia earthquake and its isotropic component. Journal of Geophysical Research: Solid Earth, 102(B9), 20423-20434.

Shelly, D. R. (2020). A high- resolution seismic catalog for the initial 2019 Ridgecrest earthquake sequence: Foreshocks, aftershocks, and faulting complexity. Seismological Research Letters, 91(4), 1971-1978.

Sheng, S., \& Meng, L. (2020). Stress Field Variation During the 2019 Ridgecrest Earthquake Sequence. Geophysical Research Letters, 47(15), e2020GL087722.

Sibson, R. H. (1994). Crustal stress, faulting and fluid flow. Geological Society, London, Special Publications, 78(1), 69-84.

This article is protected by copyright. All rights reserved. 
Spudich, P., \& Chiou, B. S. (2008). Directivity in NGA earthquake ground motions: Analysis using isochrone theory. Earthquake Spectra, 24(1), 279-298.

Stierle, E., Bohnhoff, M., \& Vavryčuk, V. (2014). Resolution of non-double-couple components in the seismic moment tensor using regional networks-II: application to aftershocks of the 1999 M w 7.4 Izmit earthquake. Geophysical Journal International, 196(3), 1878-1888.

Stroujkova, A. (2018). Rock Damage and Seismic Radiation: A Case Study of the Chemical Explosions in New HampshireA Case Study of the Chemical Explosions in New Hampshire. Bulletin of the Seismological Society of America, 108(6), 3598-3611.

Tape, W., \& Tape, C. (2012). A geometric comparison of source-type plots for moment tensors. Geophysical Journal International, 190(1), 499-510.

Tsai, V. C., \& Hirth, G. (2020). Elastic impact consequences for high- frequency earthquake ground motion. Geophysical Research Letters, 47(5), e2019GL086302.

Vavryčuk, V. (2002). Non-double-couple earthquakes of 1997 January in West Bohemia, Czech Republic: evidence of tensile faulting. Geophysical Journal International, 149(2), 364-373.

Vavryčuk, V. (2005). Focal mechanisms in anisotropic media. Geophysical Journal International, 161(2), 334-346.

Vavryčuk, V., Bohnhoff, M., Jechumtálová, Z., Kolář, P., \& Š́lený, J. (2008). Non-doublecouple mechanisms of microearthquakes induced during the 2000 injection experiment at the KTB site, Germany: A result of tensile faulting or anisotropy of a rock?. Tectonophysics, 456(1-2), 74-93.

Wang, X., \& Zhan, Z. (2020a). Moving from 1-D to 3-D velocity model: automated waveformbased earthquake moment tensor inversion in the Los Angeles region. Geophysical Journal International, 220(1), 218-234.

Wang, X., \& Zhan, Z. (2020b). Seismotectonics and Fault Geometries of the 2019 Ridgecrest Sequence: Insight From Aftershock Moment Tensor Catalog Using 3- D Green's Functions. Journal of Geophysical Research: Solid Earth, 125(5), e2020JB019577.

$\mathrm{Xu}$, X., Sandwell, D. T., \& Smith- Konter, B. (2020). Coseismic displacements and surface fractures from Sentinel- 1 InSAR: 2019 Ridgecrest earthquakes. Seismological Research Letters, 91(4), 1979-1985.

Zhan, Z., Helmberger, D., Simons, M., Kanamori, H., Wu, W., Cubas, N., ... \& Culaciati, F. H. O. (2012). Anomalously steep dips of earthquakes in the 2011 Tohoku-Oki source region and possible explanations. Earth and Planetary Science Letters, 353, 121-133.

Zhu, L., \& Ben-Zion, Y. (2013). Parametrization of general seismic potency and moment tensors for source inversion of seismic waveform data. Geophysical Journal International, 194(2), 839-843.

Zhu, L., \& Helmberger, D. V. (1996). Advancement in source estimation techniques using broadband regional seismograms. Bulletin of the Seismological Society of America, 86(5), 1634-1641.

Zhu, L., \& Zhou, X. (2016). Seismic moment tensor inversion using 3D velocity model and its application to the 2013 Lushan earthquake sequence. Physics and Chemistry of the Earth, Parts $A / B / C, 95,10-18$.

Figure 1. Map view of moment tensors of $224 M \geq 3.0$ events in the $2019 M_{\mathrm{w}} 7.1$ Ridgecrest earthquake sequence colored by the percentage of (a) CLVD component and (b) ISO component.

This article is protected by copyright. All rights reserved. 
(c) Distribution of the epicenters of the analyzed events as a function of time and distance along AA' colored by the percentage of ISO components.

Figure 2. Full moment tensor inversion results for the 2019/07/05 12:38 $M_{\mathrm{w}} 4.1$ event. (a) Map view of the earthquake location (yellow star) and seismic stations (squares) used in the study. Stations are colored by the average waveform cross-correlation (avgCC). (b) The number of waveforms that can be fitted (with the $\mathrm{CC}$ larger than 70\%), the avgCC, and the relative waveform misfit (relative avgRMS) as a function of focal depth and moment tensor solution, indicate a well-constrained focal depth of $\sim 9.5 \mathrm{~km}$. (c) Distribution of misfit in the moment tensor lune-diagram. (d) Waveform fitting at different stations. The black, red, and blue colors indicate data, synthetics, and the waveforms discarded in the automatic data selection, respectively. Phase components from left to right are radial Pnl (Pr), vertical Pnl (Pz), vertical surface waves $(\mathrm{Sz})$, radial surface waves $(\mathrm{Sr})$, and tangential surface waves $(\mathrm{Sh})$.

Figure 3. The percentage of relative misfit changes (RMC) of moment tensor inversions using (a) pure deviatoric (DC + CLVD) sources compared with pure DC sources $\left(R M C_{D C+C L V D ; D C}\right)$ vs. the strengths of CLVD component $(\chi)$, (b) the RMC of full tensor sources (DC + CLVD + ISO) compared with pure deviatoric sources $\left(R M C_{D C+C L V D+I S O ; D C+C L V D}\right)$ vs. $\chi$, (c) the RMC of DC+ ISO sources compared with pure DC sources $\left(R M C_{D C+I S O ; D C}\right)$ vs. the strengths of ISO component $(\zeta)$, and (d) the RMC of full tensor sources (DC + CLVD + ISO) compared with pure deviatoric sources $\left(R M C_{D C+C L V D+I S O ; D C+C L V D}\right)$ vs. $\zeta$. (e) The strengths of CLVD component $(\chi)$ obtained with and without ISO component. (f) The strengths of ISO component ( $\zeta$ ) obtained with and without CLVD component.

Figure 4. Variations of the percentage of ISO (red symbols) and CLVD (blue symbols) components as a function of minimum station distance cutoff for (a) three events with significant ISO component and (b) three events without significant ISO component. The beachballs on the upper side show the best-fitting double-couple solutions for different station cutoffs.

This article is protected by copyright. All rights reserved. 


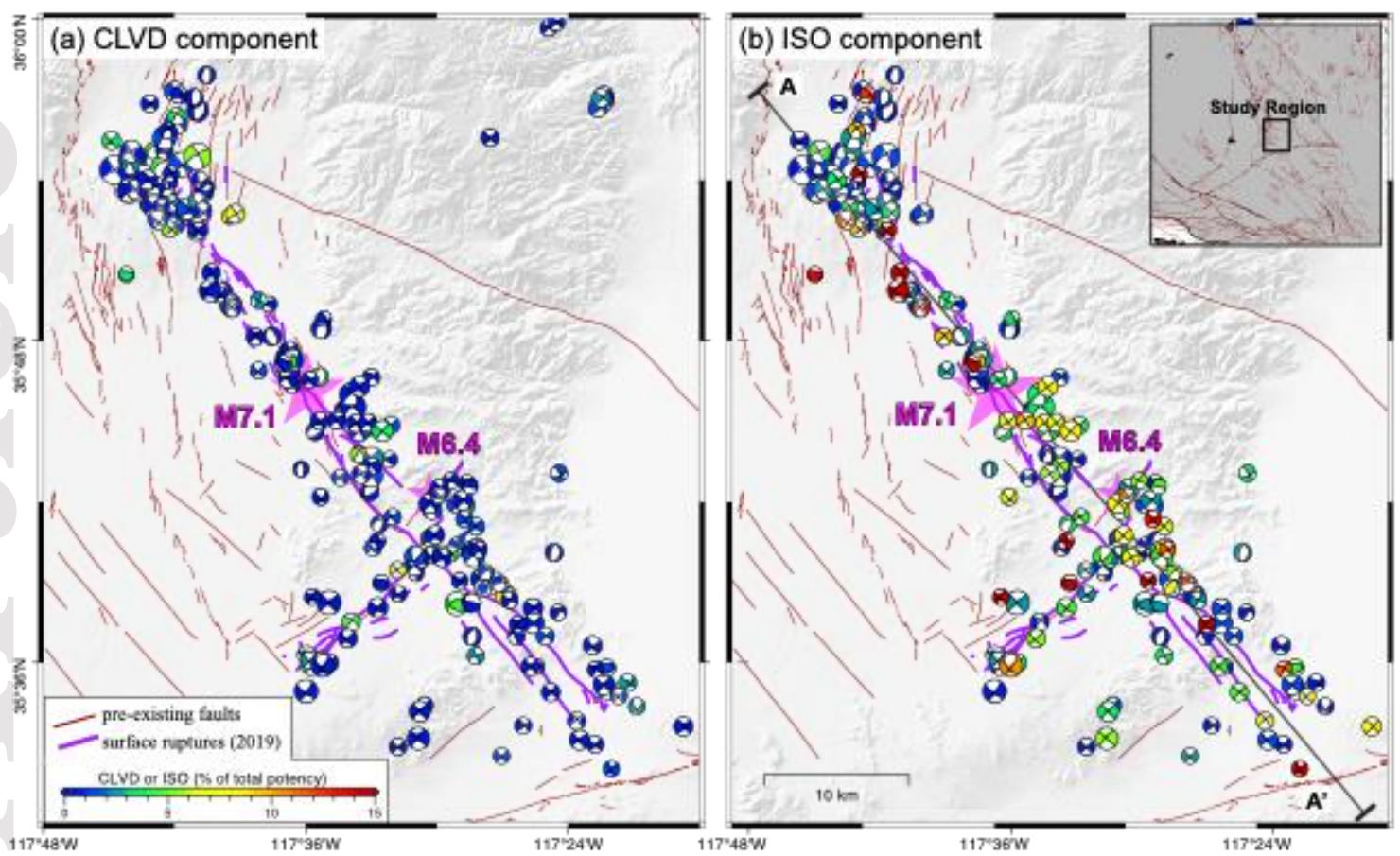

(c) Spatial and temporal variations in ISO components

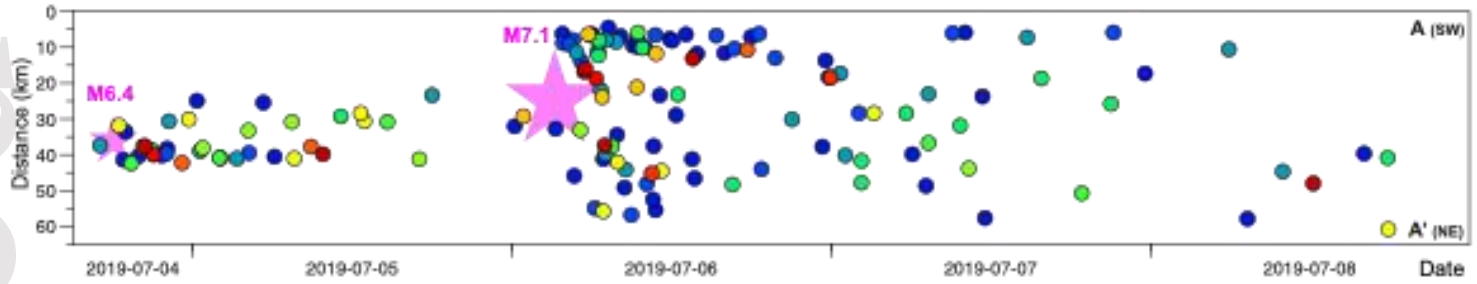

Figure 1. Map view of moment tensors of $224 M \geq 3.0$ events in the $2019 M_{\mathrm{w}} 7.1$ Ridgecrest earthquake sequence colored by the percentage of (a) CLVD component and (b) ISO component. (c) Distribution of the epicenters of the analyzed events as a function of time and distance along AA' colored by the percentage of ISO components.

This article is protected by copyright. All rights reserved. 
(a) $2019 / 07 / 0512: 38 \mathrm{Mw} 4.10$ Body wave: $0.06-0.30 \mathrm{~Hz}$; Surface wave: $0.06-0.20 \mathrm{~Hz}$;

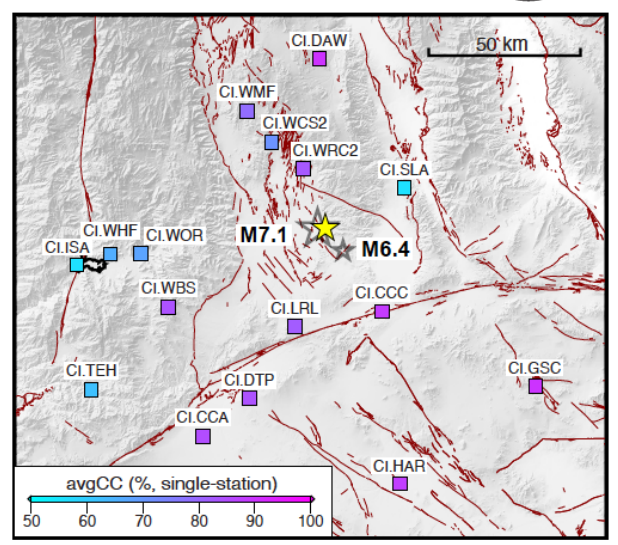

(d)

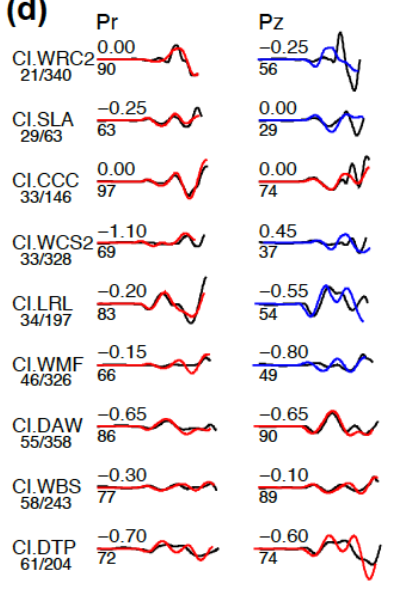

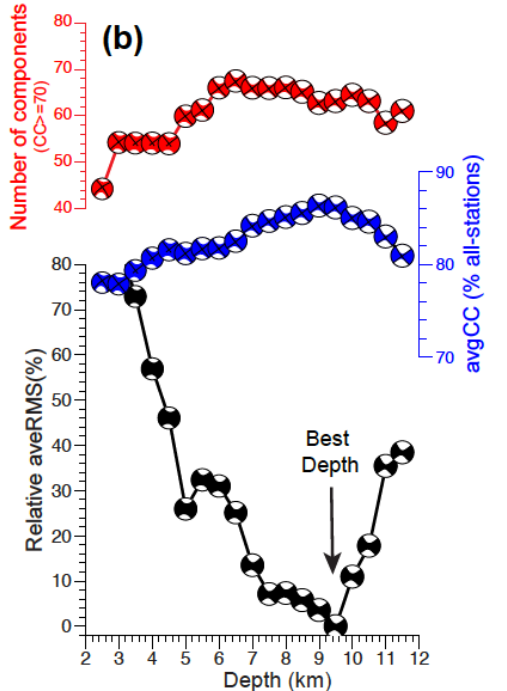
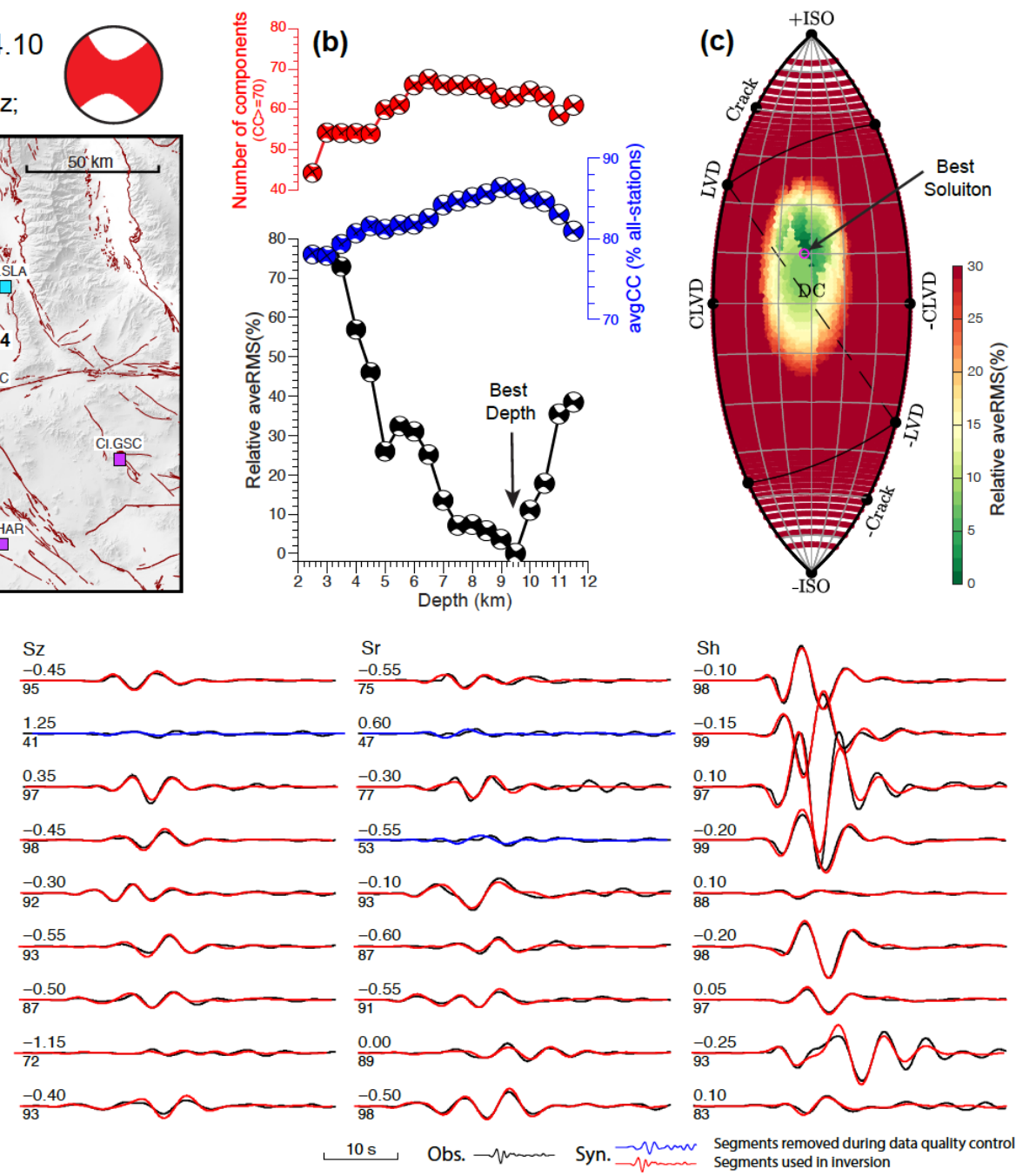

Figure 2. Full moment tensor inversion results for the 2019/07/05 12:38 $M_{\mathrm{w}} 4.1$ event. (a) Map view of the earthquake location (yellow star) and seismic stations (squares) used in the study. Stations are colored by the average waveform cross-correlation (avgCC). (b) The number of waveforms that can be fitted (with the CC larger than 70\%), the avgCC, and the relative waveform misfit (relative avgRMS) as a function of focal depth and moment tensor solution, indicate a well-constrained focal depth of $\sim 9.5 \mathrm{~km}$. (c) Distribution of misfit in the moment tensor lune-diagram. (d) Waveform fitting at different stations. The black, red, and blue colors indicate data, synthetics, and the waveforms discarded in the automatic data selection, respectively. Phase components from left to right are radial Pnl (Pr), vertical Pnl (Pz), vertical surface waves $(\mathrm{Sz})$, radial surface waves $(\mathrm{Sr})$, and tangential surface waves $(\mathrm{Sh})$.

This article is protected by copyright. All rights reserved. 

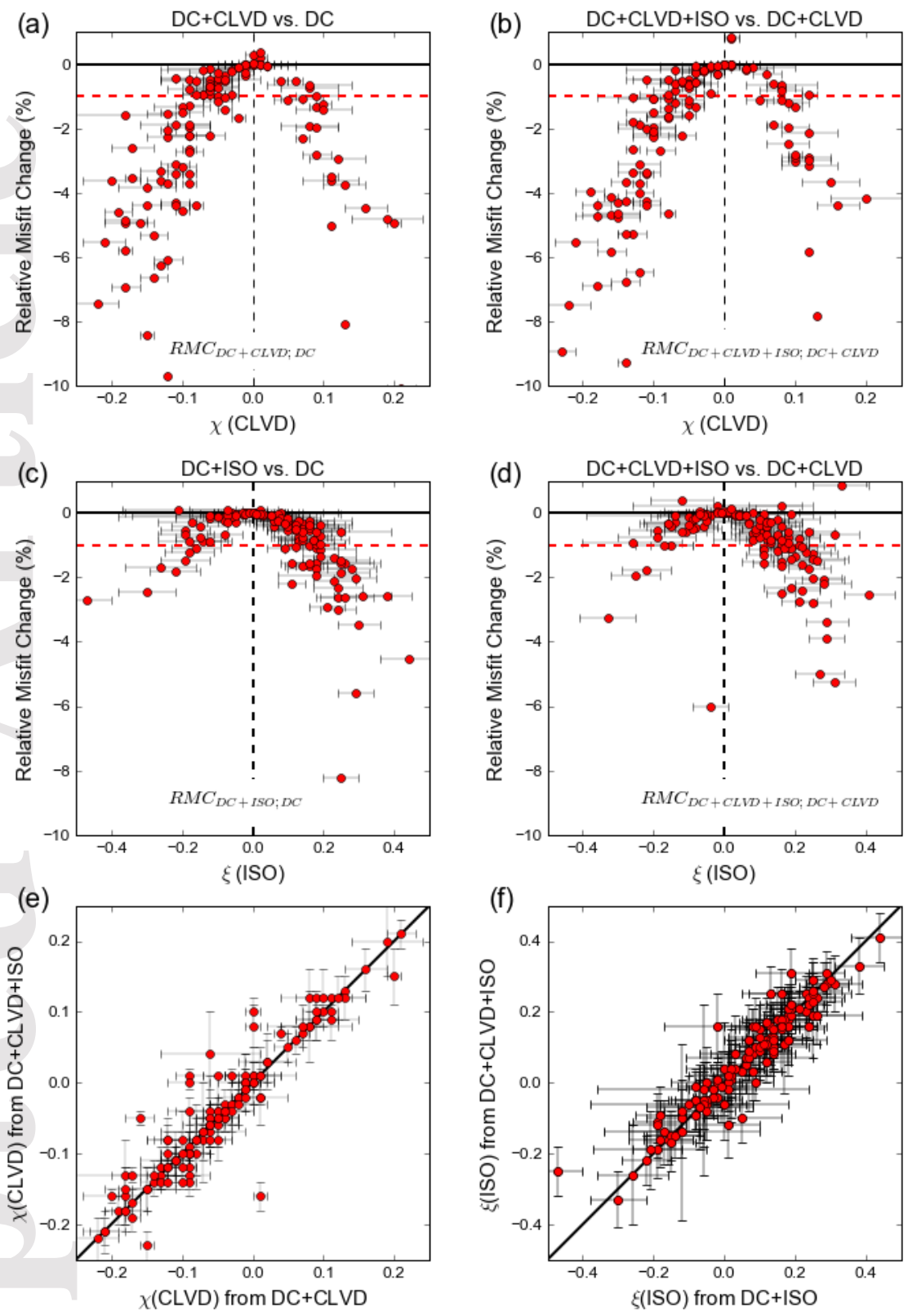

Figure 3. The percentage of relative misfit changes (RMC) of moment tensor inversions using (a) pure deviatoric (DC + CLVD) sources compared with pure DC sources $\left(R M C_{D C+C L V D ; D C}\right)$ vs. the strengths of CLVD component $(\chi)$, (b) the RMC of full tensor sources (DC + CLVD + ISO) compared with pure deviatoric sources $\left(R M C_{D C+C L V D+I S O ; D C+C L V D}\right)$ vs. $\chi$, (c) the RMC of DC+ ISO sources compared with pure DC sources $\left(R M C_{D C+I S O ; D C}\right)$ vs. the strengths of ISO component $(\zeta)$, and (d) the RMC of full tensor sources (DC + CLVD + ISO) compared with pure deviatoric sources $\left(R M C_{D C+C L V D+I S O ; D C+C L V D}\right)$ vs. $\zeta$. (e) The strengths of CLVD component $(\chi)$ obtained with and without ISO component. (f) The strengths of ISO component $(\zeta)$ obtained with and without CLVD component.

This article is protected by copyright. All rights reserved. 


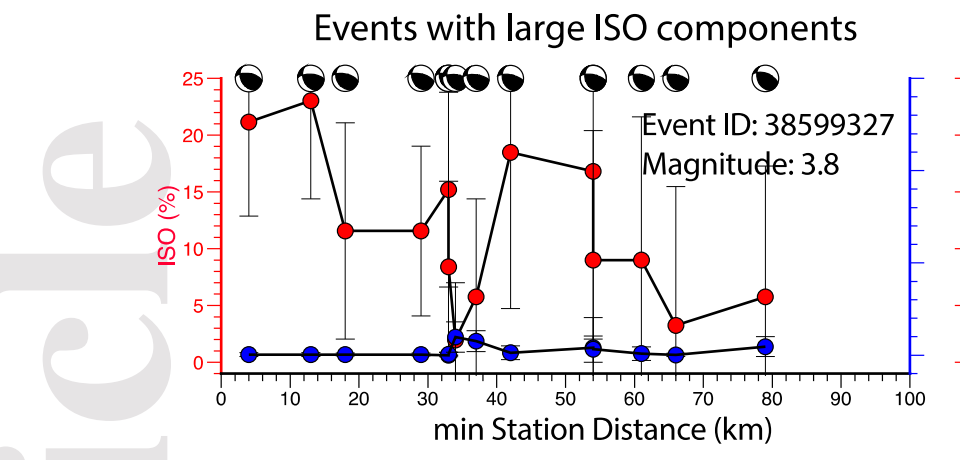

Events with small ISO components
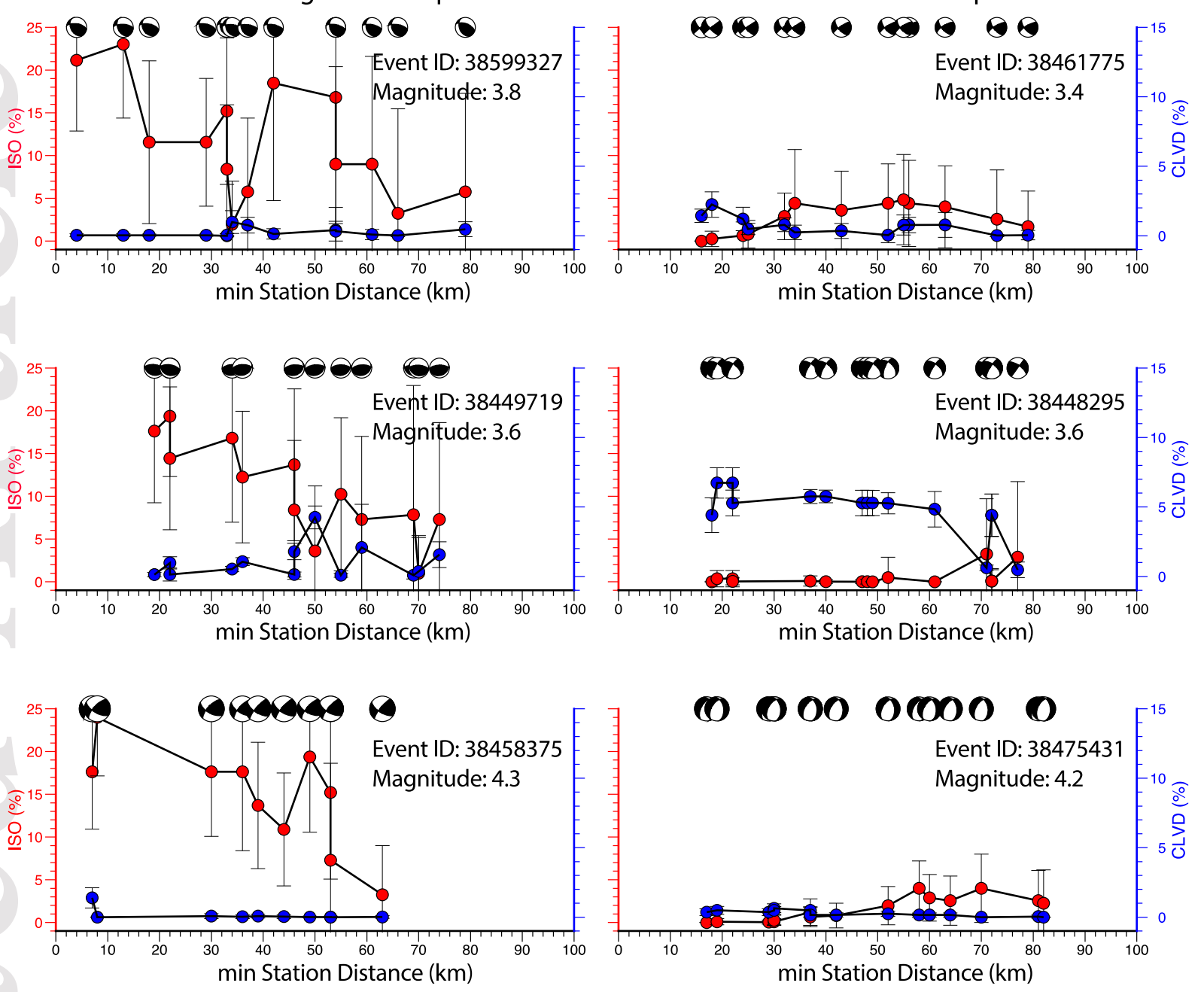

Figure 4. Variations of the percentage of ISO (red symbols) and CLVD (blue symbols) components as a function of minimum station distance cutoff for (a) three events with significant ISO component and (b) three events without significant ISO component. The beachballs on the upper side show the best-fitting double-couple solutions for different station cutoffs.

This article is protected by copyright. All rights reserved. 